American Journal of Agricultural and Biological Science 2(2): 123-129, 2007

ISSN 1557-4989

(C) 2007 Science Publications

\title{
Inoculation of a Poultry Isolate Salmonella enteritidis on Egg Vitelline Membrane: Survival and Growth in Egg Components after Different Refrigeration Storage Times
}

\author{
${ }^{1,2}$ Z. R. Howard, ${ }^{1,2}$ R.W. Moore, ${ }^{1,3}$ I.B. Zabala Diaz, ${ }^{1,4}$ W.K. Kim, ${ }^{1,5}$ S.G. Birkhold \\ ${ }^{6}$ J.A. Byrd, ${ }^{6}$ L.F. Kubena, ${ }^{6}$ D.J. Nisbet and ${ }^{1,7}$ S.C. Ricke \\ ${ }^{1}$ Texas A\&M University Department of Poultry Science, College Station, TX 77843 \\ ${ }^{2}$ Current address: USDA ARS Southeast Poultry Research Laboratory Athens, GA, 30605 \\ ${ }^{3}$ Current address: Departamento de Biologia, Facultad Experimental de Ciencias, Universidad del Zulia \\ Maracaibo, Venezuela \\ ${ }^{4}$ Current address: Dept. of Cardiology, Geffen School of Medicine, University of California \\ Los Angeles, CA 90995 \\ ${ }^{5}$ Current address: Nestlé Purina PetCare, 3916 Pettis Road, St. Joseph, MO, 64503 \\ ${ }^{6}$ USDA-ARS, SPARC, FFSRU, 2881 F\&B Road, College Station, TX 77845 \\ ${ }^{7}$ Current address: Center for Food Safety and Microbiology, IFSE, Dept. of Food Science \\ University of Arkansas, Fayetteville, AR 72704-5690
}

\begin{abstract}
An in vitro study was designed to determine the extent of Salmonella enterica serovar enteritidis survival and growth permissiveness in egg components isolated from shell eggs held at refrigeration temperature over an 8 week time period. Eggs were collected from a commercial laying facility at one-week intervals for eight weeks and stored at refrigeration temperature. After storage, eggs were dipped in ethanol, cracked aseptically and separated into yolk and albumen samples. $S$. enteritidis resistant to novobiocin and nalidixic acid were inoculated on to the surface of the yolk membrane at a concentration of approximately $10^{6} \mathrm{CFU} \mathrm{mL} \mathrm{m}^{-1}$. Yolks were then covered with albumen and incubated for $24 \mathrm{hrs}$ at $25^{\circ} \mathrm{C}$. After incubation, eggs were separated into component parts. Samples were removed from yolk, albumen and yolk membrane and diluted 10-fold in sterile phosphate buffered saline. In albumen, $S$. enteritidis counts were increased in weeks 3 and 8 compared to week 1 (trial 2). The frequency of eggs exhibiting net growth of $S$. enteritidis in albumen occurred at week 7 versus weeks 0 and 1 in trial 1 and weeks 3 and 8 versus weeks 0 and 2 in trial 2 . In the membrane fraction, the frequency of eggs exhibiting net growth of $S$. enteritidis occurred at weeks 5 and 8 versus week 0 in trial 2. In the yolk fractions, $S$. enteritidis counts recovered from week 6 eggs were significantly higher $(\mathrm{P}<0.05)$ than those of weeks $0,2,3$ and 7 (trial 2) and the number of detectable $S$. enteritidis positive eggs were greater in week 8 than week 5 in trial 1 . This suggests that egg components recovered from aged eggs stored at refrigeration temperatures infrequently supported $S$. enteritidis net growth but generally did not inhibit survivability.
\end{abstract}

Keywords:

\section{INTRODUCTION}

Salmonella enterica serovar Enteritidis $(S$. enteritidis) accounts for over $65 \%$ of all human serotype isolates worldwide ${ }^{[1]}$. Beginning in the late 1970's infections of this pathogen spread over the next ten years from New England to the remainder of the United States ${ }^{[2,3]}$. Although broiler chicken carcasses have shown recent increases in this serotype, Grade A shell eggs are usually considered the most common vehicle for the transmission of $S$. enteritidis ${ }^{[3-5]}$. Management practices such as feed withdrawal molt induction in laying hens to initiate multiple egg laying cycles have been identified as causes for increased $S$. enteritidis colonization in the gastrointestinal tract ${ }^{[6-8]}$. Development of alternative molt diet regimes that avoid feed withdrawal have been shown to limit $S$. enteritidis colonization and infection in susceptible laying hens ${ }^{[9-}$

16]. However, despite the availability of these management options and introduction of egg quality

Corresponding Author: $\quad$ Dr. Steven C. Ricke, Food Science Dept., University of Arkansas, 2650 North Young Avenue, Fayetteville, AR 72704-5690, Tel:: (479)575-4678, Fax: (479) 575-6936 
assurance programs, the numbers and incidence continues to persist in some parts of the United States ${ }^{[2]}$. This continued trend in disease incidence requires understanding the environmental conditions which favor $S$. enteritidis establishment and persistence in eggs and egg components.

Albumen or egg white possesses several chemical defenses that limit growth of pathogens including lysozyme, ovotransferrin, avidin and ovomucoid ${ }^{[17]}$. Ovotransferrin and iron availability are believed to play a major role in limiting $S$. enteritidis ${ }^{[18]}$. Although the egg albumen is relatively hostile to $S$. enteritidis multiplication there is evidence that $S$. enteritidis is capable of long term survival in the internal egg environment. In a study by Lock and Board ${ }^{[19]}$ they suggested that salmonellae introduced onto the air cell of an egg could survive for up to 17 days at refrigeration temperatures. Rizk et al. ${ }^{[20]}$ observed that at high relative humidity salmonellae may be able to survive refrigeration temperature. As length of storage time of shell eggs increases, albumen quality and vitelline membrane strength deteriorate $e^{[21,22]}$. The breakdown of the vitelline membrane could either allow bacteria such as $S$. enteritidis to gain access to yolk material, or allow nutrient compounds such as iron to leak out into the albumen ${ }^{[23]}$.

Previously we observed that serotype $S$. typhimurium could survive and exhibit net growth on egg components during an 8 week storage period under refrigeration conditions ${ }^{[24]}$. This combination of increased susceptibility for egg deterioration at advanced storage times with the ability of $S$. typhimurium to survive refrigeration makes understanding the time line of an egg's S. enteritidis survival and growth permissiveness critical. We hypothesize that an increase in the refrigeration time could increase the susceptibility to $S$. enteritidis contamination. The objective of this in vitro study was to use similar vitelline membrane inoculation approaches as our previous work with $S$. typhimurium $^{[24]}$ and determine whether sufficient deterioration occurs in refrigerated eggs over an 8 week time period such that individual egg components will permit survival and net growth of $S$. enteritidis after inoculation on the vitelline membrane.

\section{MATERIALS AND METHODS}

Egg collection: Over the course of eight weeks, eggs were collected from a commercial flock of 60 week old single comb white leghorn hens at one week intervals. Eggs were stored at refrigeration temperatures of $4^{\circ} \mathrm{C}$ under a relative humidity of $97 \%$ for a period of zero to eight weeks. After refrigerated storage, eggs were separated into time points of $0,1,2,3,4,5,6,7$ and 8 week old eggs and inoculated with $S$. enteritidis prepared as described in the following sections.

Bacterial preparation: A strain of $S$. enteritidis isolated from poultry at the University of Iowa, (Ames, Iowa), resistant to novobiocin and nalidixic acid and known to be infective in laying hens ${ }^{[10,13-16]}$ was grown overnight in Difco ${ }^{\mathrm{TM}}$ Tryptic Soy Broth (Difco Laboratories, Detroit, MI, USA). After incubation, cells were centrifuged for $10 \mathrm{~min}$ at $8000 \mathrm{rpm}$. Supernatant was discarded and cells were resuspended in $6 \mathrm{~mL}$ of sterile phosphate buffered saline. The centrifuge and resuspension steps were subsequently repeated. The final concentration of cells was $10^{6} \mathrm{CFU} \mathrm{mL}^{-1}$.

Sampling method: Eggs were dipped in 95\% ethanol in order to remove surface contamination of the shell ${ }^{[25]}$. Eggs were then aseptically cracked and separated into yolk and albumen components in sterile vessels. A $0.01 \mathrm{~mL}$ aliquot of $S$. enteritidis prepared as stated previously was then placed directly on the exposed vitelline membrane of the eggs to be sampled. After holding the inoculated yolk for $5 \mathrm{~min}$ to allow bacterial attachment, albumen was added back to the sterile vessel. Ten eggs were inoculated at each time point. Inoculated eggs were incubated at $25^{\circ} \mathrm{C}$ for 24 hrs. In addition, one egg was sacrificed following the 5 min holding period in order to determine initial population methods of bacteria that survived transfer into egg components. To determine that eggs used were initially free of Salmonella, one egg was sampled prior to inoculation with bacteria. Two separate trials were run using this method and the $S$. enteritidis poultry isolate. Both trials used the same set of saved eggs. For each trial 10 eggs were inoculated and later sampled for each time point from 0 to 8 weeks of storage.

After 24 hrs of incubation eggs for all time points including the zero time, stored eggs were again separated into component parts of yolk and albumen. A $1 \mathrm{~mL}$ sample of albumen was then drawn using a $3 \mathrm{~mL}$ syringe. The following sample method previously described by Gast and Holt ${ }^{[26]}$ was used to gather yolk samples. A flame heated spatula was applied to the vitelline membrane. This created a sterile opening through which a 16-gauge needle could pass ${ }^{[26]}$. Membrane samples were taken by gathering the membrane with flamed rat tooth forceps followed by stomaching with $5 \mathrm{~mL}$ of sterile phosphate buffered samples.

All samples were subsequently diluted ten fold in sterile phosphate buffered saline at neutral $\mathrm{pH}$ and 
plated on Brilliant Green Agar (BGA, Difco Laboratories, Detroit, MI, USA) with novobiocin and nalidixic acid $\left(25 \mu \mathrm{g} \mathrm{mL}^{-1}\right)$. Plates were inoculated with $0.01 \mathrm{~mL}$ of each dilution and stored for $48 \mathrm{hrs}$ at $37^{\circ} \mathrm{C}$. Colonies of typical Salmonella morphology were enumerated on BGA.

Statistical analysis: Each trial was designed to consist of samples taken from ten eggs per week. However, because of the fragile nature of the egg components it was not always possible to recover intact egg components. Therefore most data statistically analyzed in this study were based on less than ten eggs and reported accordingly. Population counts from multiple plates of the same dilution series were averaged to give total colony counts from each individual egg. $S$. enteritidis counts were subjected to one-way analysis of variance using GLM procedure of SAS (SAS Institute, 2001). The number of eggs containing detectable $S$. enteritidis and the number of eggs containing higher $S$. enteritidis than the initial inoculation level were analyzed using Chi square analysis. Significant differences among the refrigeration storage times were reported at the 0.05 level.

\section{RESULTS AND DISCUSSION}

Albumen: Albumen S. enteritidis counts over time, number of eggs containing detectable $S$. enteritidis and number of eggs containing higher $S$. enteritidis than the initial inoculation level are shown in Table 1.S. enteritidis was detected in all eggs from all weeks in both trials. In trial 1 there were no significant differences $(\mathrm{P}>0.05)$ in $S$. enteritidis counts among the eight weeks. However, frequency of $S$. enteritidis positive eggs above the original inoculation number $\left(10^{6}\right.$ colony forming unit) at week 7 was significantly higher $(\mathrm{P}<0.05)$ than eggs from weeks 0 and 1 . In trial 2 , S. enteritidis counts of weeks 3 and 8 were significantly higher than eggs from week 1 . In trial 2, frequency of $S$. enteritidis positive eggs above the original inoculation number $\left(10^{6}\right.$ colony forming unit) at week 3 was significantly higher $(\mathrm{P}<0.05)$ than weeks 0 and 2. Frequency of $S$. enteritidis positive eggs above the original inoculation number at week 8 was significantly higher $(\mathrm{P}<0.01)$ than week 0 and 2 .

We also observed net growth of S. typhimurium in albumen in some eggs at different weeks ${ }^{[24]}$. Gast and Holt ${ }^{[26-28]}$ showed that fresh albumen is inhospitable to the growth of $S$. enteritidis. Hara-Kudo et al. ${ }^{[29]}$ reported that $S$. enteritidis grew less frequently in eggs stored at $10{ }^{\circ} \mathrm{C}$ than eggs stored at either 20 or $30^{\circ} \mathrm{C}$ and $S$. enteritidis grew more preferably in albumen of cracked eggs versus intact eggs. Fleischman et al. ${ }^{[30]}$ did not observe in vitro growth of $S$. enteritidis inoculated in albumen incubated over 2 days at 4 and 8 ${ }^{\circ} \mathrm{C}$. It is noteworthy that using the same amount of bacterial cells in the current study, both fresh eggs and those from different storage times were relatively resistant to $S$. enteritidis multiplication in the albumen. However, as indicated by the $100 \%$ detection frequency observed in the current study, S. enteritidis was still capable of survival in the albumen regardless of the age of the eggs from which the albumen was recovered. Murase et al. ${ }^{[11]}$ also observed survival of $S$. enteritidis after inoculation into separated albumen from eggs stored at $4{ }^{\circ} \mathrm{C}$ for 1 to 4 weeks. This survivability would seem to reinforce the idea that if the albumen deteriorates over time, the potential exists for $S$. enteritidis to multiply in the albumen.

Vitelline membrane: Membrane $S$. enteritidis counts over time, number of eggs containing detectable $S$. enteritidis and number of eggs containing higher $S$. enteritidis than the initial inoculation level are shown in Table 2. S. enteritidis was detectable in all eggs for all weeks in both trials. Vitelline membrane counts from both trials showed that there were no significant differences $(\mathrm{P}>0.05)$ in enumerated $S$. enteritidis populations recovered from eggs stored over time. Likewise no significant increases $(\mathrm{P}>0.05)$ in frequencies of eggs exhibiting net growth of $S$. enteritidis were observed in trial 1. The lack of significance in this sample set could be due to the initial dilution of vitelline membrane sample with $5 \mathrm{~mL}$ of sterile phosphate buffered saline. In addition, it was not possible to remove all yolk material from the membrane prior to sampling; this may have led to a variation in sample volume that could have affected variability in the counts taken. Fleischman et al. ${ }^{[30]}$ did not observe in vitro growth of $S$. enteritidis inoculated on vitelline membrane incubated over 2 days at 4 and $8^{\circ} \mathrm{C}$.

In trial 2 frequencies of $S$. enteritidis positive eggs above the original inoculation level $\left(10^{6}\right.$ colony forming unit) at weeks 5 and 8 were higher than from eggs at week $0(\mathrm{P}<0.05)$. We also observed net growth of $S$. typhimurium in the vitelline membrane in eggs from different weeks of refrigerated storage ${ }^{[24]}$. Immediate refrigeration at $7{ }^{\circ} \mathrm{C}$ followed by $24 \mathrm{hrs}$ of refrigerated storage at this temperature has been shown to prevent the in vitro penetration of $S$. enteritidis through the yolk membrane ${ }^{[32]}$. However, studies by Kirunda and $\mathrm{McKe}^{[22]}$ have demonstrated that with increased storage time, the strength of the vitelline membrane is significantly decreased. Consequently, changes in membrane strength and composition as a 
Am. J. Agri. \& Biol., 2(2): 123-129, 2007

Table 1: Albumen S. enteritidis (SE) counts over time, number of eggs containing detetable S. enteritidis and number of eggs containing higher S. entertidis than initial inoculation

\begin{tabular}{|c|c|c|c|c|c|c|}
\hline \multirow{2}{*}{$\begin{array}{l}\text { Inoculation time } \\
\text { (Week) }\end{array}$} & \multicolumn{3}{|l|}{ Trial 1} & \multicolumn{3}{|l|}{ Trial 2} \\
\hline & $\log \mathrm{cfu} / \mathrm{mL}$ & $\begin{array}{l}\text { Detectable SE } \\
\text { in eggs/total (\%) }\end{array}$ & $\begin{array}{l}\text { SE net growth in } \\
\text { eggs/total (\%) }\end{array}$ & $\log \mathrm{cfu} / \mathrm{mL}$ & $\begin{array}{l}\text { Detectable SE } \\
\text { in eggs/total (\%) }\end{array}$ & $\begin{array}{l}\text { SE net growth in } \\
\text { eggs/total }(\%)\end{array}$ \\
\hline 0 & $4.84 \pm 0.23$ & $8 / 8(100)$ & $0 / 8(0)$ & $4.62 \pm 0.16^{\mathrm{ab}}$ & $8 / 8(100)$ & $0 / 8(0)$ \\
\hline 1 & $4.56 \pm 0.19$ & $8 / 8(100)$ & $0 / 8(0)$ & $4.39 \pm 0.63^{\mathrm{b}}$ & $9 / 9(100)$ & $2 / 9(22)$ \\
\hline 2 & $5.00 \pm 0.65$ & $5 / 5(100)$ & $1 / 5(20)$ & $4.69 \pm 0.29^{\mathrm{ab}}$ & $8 / 8(100)$ & $0 / 8(0)$ \\
\hline 3 & $4.92 \pm 0.34$ & $4 / 4(100)$ & $0 / 4(0)$ & $5.87 \pm 0.57^{\mathrm{a}}$ & $7 / 7(100)$ & $4 / 7(57)^{* *}$ \\
\hline 4 & $5.13 \pm 0.61$ & $10 / 10(100)$ & $3 / 10(30)$ & $4.71 \pm 0.52^{\mathrm{ab}}$ & $8 / 8(100)$ & $1 / 8(13)$ \\
\hline 5 & $5.27 \pm 0.45$ & $9 / 9(100)$ & $3 / 9(33)$ & $4.94 \pm 0.23^{\mathrm{ab}}$ & $7 / 7(100)$ & $0 / 7(0)$ \\
\hline 6 & $4.95 \pm 0.66$ & $6 / 6(100)$ & $2 / 6(33)$ & $5.19 \pm 0.30^{\mathrm{ab}}$ & $5 / 5(100)$ & $1 / 5(20)$ \\
\hline 7 & $5.91 \pm 0.82$ & $7 / 7(100)$ & $3 / 7(43)^{*}$ & $4.64 \pm 0.42^{\mathrm{ab}}$ & $9 / 9(100)$ & $1 / 9(11)$ \\
\hline 8 & $4.83 \pm 0.26$ & $7 / 7(100)$ & $1 / 7(14)$ & $6.05 \pm 0.37^{\mathrm{a}}$ & $8 / 8(100)$ & $5 / 8(63)^{* * *}$ \\
\hline
\end{tabular}

${ }^{\mathrm{a}-\mathrm{b}}$ Means within a column with different superscripts differ significantly $(\mathrm{P}<0.05)$.

* Significant difference compared to weeks 0 and $1(\mathrm{P}<0.05)$

** Significant difference compared to weeks 0 and $2(\mathrm{P}<0.05)$

$* * *$ Significant difference compared to weeks 0 and $2(\mathrm{P}<0.01)$

Table 2: $\quad$ Membrane S. enteritidis (SE) counts over time, number of eggs containing detectable S. enteritidis and number of eggs containing higher S. entertiditis than initial inoculation level

\begin{tabular}{|c|c|c|c|c|c|c|}
\hline \multirow{2}{*}{$\begin{array}{l}\text { Inoculation time } \\
\text { (Week) }\end{array}$} & \multicolumn{3}{|l|}{ Trial 1} & \multicolumn{3}{|l|}{ Trial 2} \\
\hline & $\log \mathrm{cfu} / \mathrm{mL}$ & $\begin{array}{l}\text { Detectable SE } \\
\text { in eggs/total (\%) }\end{array}$ & $\begin{array}{l}\text { SE net growth in } \\
\text { eggs/total }(\%)\end{array}$ & $\log \mathrm{cfu} / \mathrm{mL}$ & $\begin{array}{l}\text { Detectable SE } \\
\text { in eggs/total }(\%)\end{array}$ & $\begin{array}{l}\text { SE net growth in } \\
\text { eggs/total }(\%)\end{array}$ \\
\hline 0 & $5.28 \pm 0.21$ & $9 / 9(100)$ & $0 / 9(0)$ & $5.40 \pm 0.20$ & $9 / 9(100)$ & $0 / 9(0)$ \\
\hline 1 & $5.20 \pm 0.12$ & $9 / 9(100)$ & $0 / 9(0)$ & $5.16 \pm 0.25$ & $9 / 9(100)$ & $1 / 9(11)$ \\
\hline 2 & $5.03 \pm 0.37$ & $7 / 7(100)$ & $2 / 7(29)$ & $5.02 \pm 0.34$ & $8 / 8(100)$ & $1 / 8(12)$ \\
\hline 3 & $4.58 \pm 0.21$ & 9/9(100) & $0 / 9(0)$ & $5.33 \pm 0.26$ & $10 / 10(100)$ & $2 / 10(20)$ \\
\hline 4 & $4.98 \pm 0.20$ & $10 / 10(100)$ & $0 / 10(0)$ & $5.48 \pm 0.23$ & $9 / 9(100)$ & $2 / 9(22)$ \\
\hline 5 & $5.23 \pm 0.27$ & $9 / 9(100)$ & $2 / 9(22)$ & $5.86 \pm 0.39$ & $6 / 6(100)$ & $3 / 6(50)^{*}$ \\
\hline 6 & $4.90 \pm 0.34$ & $6 / 6(100)$ & $0 / 6(0)$ & $5.42 \pm 0.28$ & $5 / 5(100)$ & $0 / 5(0)$ \\
\hline 7 & $5.19 \pm 0.29$ & $8 / 8(100)$ & $2 / 8(25)$ & $5.32 \pm 0.21$ & $9 / 9(100)$ & $1 / 9(11)$ \\
\hline 8 & $5.00 \pm 0.31$ & $8 / 8(100)$ & $1 / 8(12)$ & $5.56 \pm 0.30$ & $8 / 8(100)$ & $4 / 8(50)^{*}$ \\
\hline
\end{tabular}

* Significant difference compared to week $0(\mathrm{P}<0.05)$

Table 3: Yolk S. enteritidis (SE) counts over time, number of eggs containing detectable S. enteritidis and number of eggs containing higher $S$. enteritidis than initial inoculation level

\begin{tabular}{|c|c|c|c|c|c|c|}
\hline \multirow{2}{*}{$\begin{array}{l}\text { Inoculation time } \\
\text { (Week) }\end{array}$} & \multicolumn{3}{|l|}{ Trial 1} & \multicolumn{3}{|l|}{ Trial 2} \\
\hline & $\log \mathrm{cfu} / \mathrm{mL}$ & $\begin{array}{l}\text { Detectable SE } \\
\text { in eggs/total (\%) }\end{array}$ & $\begin{array}{l}\text { SE net growth in } \\
\text { eggs/total }(\%)\end{array}$ & $\log \mathrm{cfu} / \mathrm{mL}$ & $\begin{array}{l}\text { Detectable SE } \\
\text { in eggs/total (\%) }\end{array}$ & $\begin{array}{l}\text { SE net growth in } \\
\text { eggs/total }(\%)\end{array}$ \\
\hline$\overline{0}$ & $0.53 \pm 0.31$ & $3 / 9(33)$ & $0 / 9(0)$ & $0.00 \pm 0.00^{\mathrm{b}}$ & $0 / 8(0)$ & $0 / 8(0)$ \\
\hline 1 & $0.00 \pm 0.00$ & $0 / 8(0)$ & $0 / 8(0)$ & $0.48 \pm 0.37^{\mathrm{ab}}$ & $2 / 9(22)$ & $0 / 9(0)$ \\
\hline 2 & $0.14 \pm 0.14$ & $1 / 7(14)$ & $0 / 7(0)$ & $0.17 \pm 0.17^{b}$ & $1 / 9(11)$ & $0 / 9(0)$ \\
\hline 3 & $0.82 \pm 0.43$ & $1 / 9(11)$ & $0 / 9(0)$ & $0.12 \pm 0.12^{\mathrm{b}}$ & $1 / 8(12)$ & $0 / 9(0)$ \\
\hline 4 & $0.59 \pm 0.59$ & $1 / 9(11)$ & $0 / 9(0)$ & $0.32 \pm 0.21^{\mathrm{ab}}$ & $2 / 8(25)$ & $0 / 8(0)$ \\
\hline 5 & $0.00 \pm 0.00$ & $0 / 9(0)$ & $0 / 9(0)$ & $0.25 \pm 0.25^{\mathrm{ab}}$ & $1 / 7(14)$ & $0 / 7(0)$ \\
\hline 6 & $0.33 \pm 0.33$ & $0 / 6(0)$ & $0 / 6(0)$ & $1.09 \pm 0.86^{\mathrm{a}}$ & $2 / 5(40)$ & $0 / 5(0)$ \\
\hline 7 & $0.00 \pm 0.00$ & $0 / 8(0)$ & $0 / 8(0)$ & $0.10 \pm 0.10^{\mathrm{b}}$ & $1 / 10(10)$ & $0 / 10(0)$ \\
\hline 8 & $1.06 \pm 0.53$ & $3 / 8(38)^{*}$ & $0 / 8(0)$ & $0.27 \pm 0.27^{\mathrm{ab}}$ & $1 / 8(12)$ & $0 / 8(0)$ \\
\hline
\end{tabular}

${ }^{a-b}$ Means within a column with different superscripts differ significantly $(\mathrm{P}<0.05)$.

* Significant difference compared to week $5(\mathrm{P}<0.05)$

function of age may occur to allow multiplication of $S$. enteritidis directly inoculated on the vitelline membrane.

Yolk: Yolk S. enteritidis counts over time, number of eggs containing detectable $S$. enteritidis and number of eggs containing higher $S$. enteritidis than the initial inoculation level are presented in Table 3. In trial 1, frequency of detectable $S$. enteritidis positive eggs at week 8 was significantly higher than eggs from week 5 $(\mathrm{P}<0.05)$ whereas there were no significant differences $(\mathrm{P}>0.05)$ in $S$. enteritidis counts and frequency of $S$. 
enteritidis positive eggs among the treatments. In trial $2, S$. enteritidis recovered populations from week 6 were significantly higher than those of weeks $0,2,3$ and 7. However, there were no significant differences $(\mathrm{P}>0.05)$ in frequencies of detectable $S$. enteritidis positive eggs or $S$. enteritidis positive eggs above the initial inoculation level. Counts taken from yolk samples in both trials were somewhat erratic over time.

Although there were significant peaks in the levels of enumerated $S$. enteritidis populations at different lengths of storage time, there were no noticeable trends in contamination levels over time. Similar trends were also observed for $S$. typhimurium in egg yolks at different weeks ${ }^{[24]}$. Weekly time points which yielded substantial differences in the current study were usually the result of only a subset of eggs within the group that supported this net growth. This is probably a reflection of the relatively few egg components in this study that permitted net growth of $S$. enteritidis. Based on in vitro studies Gast et al. ${ }^{[33]}$ reported that $S$. enteritidis and $S$. heidelberg could penetrate the vitelline membranes of contaminated eggs in egg yolks during the first day of storage at warm temperatures. Fleischman et al. ${ }^{[30]}$ did not observe in vitro growth of $S$. enteritidis inoculated egg yolk incubated over 2 days at 4 and $8{ }^{\circ} \mathrm{C}$.

\section{CONCLUSION}

In conclusion, net increases of $S$. enteritidis rarely occurred in either vitelline membrane or albumen isolated from eggs stored over an 8 week period. However, S. enteritidis populations were usually detectable and when net growth did occur in the different egg components, it usually occurred in the fractions isolated from older eggs. This response resembles the trends observed by Howard et al. ${ }^{[24]}$ for S. typhimurium inoculated onto egg components under similar experimental conditions. Previous studies with $S$. enteritidis have demonstrated that when it is introduced directly to yolk material, rapid growth is experienced ${ }^{[27,34-36]}$. Therefore, if $S$. enteritidis was able to penetrate the vitelline membrane in the current study, counts from yolk samples should have been much higher. Consequently, even though vitelline membrane deterioration may have occurred, it was apparently not severe enough in this study to produce large increases in S. enteritidis yolk counts or high frequencies of eggs exhibiting $S$. enteritidis net growth. This is supported by the reports that rapid refrigeration of eggs and long term storage at refrigeration temperatures limits growth and penetration of $S$. enteritidis into egg contents ${ }^{[32,37-}$ 39]. However, since $S$. enteritidis was generally detectable after inoculation of the albumen and vitelline membrane at each weekly interval there still exists opportunity for multiplication to occur if internal egg environmental conditions suddenly become growth permissive.

\section{ACKNOWLEDGEMENTS}

This research was supported by Hatch grant H8311 administered by the Texas Agricultural Experiment Station and USDA-NRI grant number 2002-3520111608 .

\section{REFERENCES}

1. Galanis, E., D.M.A.L.F. Wong, M.E. Patrick, N. Binsztein, A. Cieslik, T. Chalermchaikit, A. Aidara-Kane, A. Ellis, F.J. Angulo and H.C. Wegener, 2006. Web-based surveillance and global Salmonella distribution, 2000-2002. Emerging Inf. Dis., 12: 381-388.

2. Mumma, M.A, P.M. Griffin, M.I. Meltzer, C.R. Braden and R.V. Tauxe, 2004. Egg quality assurance programs and egg-associated Salmonella enteritidis infections, United States. Emerging Inf. Dis., 10: 1782-1789.

3. St. Louis, M.E., D.L. Morse, M.E. Potter, T.m. Demelfi, J.J. Guzewick, R.v. Tauxe and P.A. Blake, 1988. The emergence of grade A shell eggs as a major source of Salmonella enteritidis infections: new implications for the control of salmonellosis. J. Am. Med. Assoc., 259: 21032196.

4. Patrick, M.E., P.M. Adcock, T.M. Gomez, S.F. Altekruse, B.H. Holland, R.V. Tauxe and D.L. Swerdlow, 2004. Salmonella enteritidis infections, United States, 1985-1999. Emerging Inf. Dis., 10: 1-7.

5. Altekruse, S.F., N. Bauer, A. Chanlongbutra, R. DeSagun, A. Naugle, W. Schlosser, R. Umholtz and P. White, 2006. Salmonella enteritidis in broiler chickens, United States, 2000-2005. Emerging Inf. Dis., 12: 1848-1852.

6. Durant, J.A., D.E. Corrier, J.A. Byrd, L.H. Stanker and S.C. Ricke, 1999. Feed deprivation affects crop environment and modulates Salmonella enteritidis colonization and invasion of Leghorn hens. Appl. Environ. Microbiol., 65: 1919-1923.

7. Holt, P.S., 2003. Molting and Salmonella enterica serovar Entertidis infection: The problem and some solutions. Poult. Sci., 82: 1008-1010.

8. Ricke, S.C., 2003. The gastrointestinal tract ecology of Salmonella enteritidis colonization in molting hens. Poult. Sci., 82: 1003-1007. 
9. Seo, K.-H., P.S. Holt and R.K. Gast, 2001. Comparison of Salmonella Enteriditis infection in hens molted via long term feed withdrawal versus full-fed wheat middling. J. Food Prot., 64: 19171971.

10. Moore, R.W., S.Y. Park, L.F. Kubena, J.A. Byrd, J.L. McReynolds, M.R. Burnham, M.E.Hume, S.G. Birkhold, D.J. Nisbet and S.C. Ricke, 2004. Comparison of zinc acetate and propionate addition on gastrointestinal tract fermentation and susceptibility of laying hens to Salmonella enteritidis during forced molt. Poult. Sci., 83: 1276-1286.

11. Park, S.Y., W.K. Kim, S.G. Birkhold, L.F. Kubena, D.J. Nisbet and S.C. Ricke, 2004a. Induced moulting issues and alternative dietary strategies for the egg industry in the United States. World's Poult. Sci. J., 60: 196-209.

12. Park, S.Y., S.G. Birkhold, L.F. Kubena, D.J. Nisbet and S.C. Ricke, 2004b. Review on the role of dietary zinc in poultry nutrition, immunity and reproduction. Biological Trace Element Res., 101: 147-163.

13. Ricke, S.C., S.Y. Park, R.W. Moore, Y.M. Kwon, C.L. Woodward, J.A. Byrd, D.J. Nisbet and L.F. Kubena, 2004. Feeding low calcium and zinc molt diets sustains gastrointestinal fermentation and limits Salmonella enterica serovar enteritidis colonization in laying hens. J. Food Safety, 24: 291-308.

14. Woodward, C.L., Y.M. Kwon, L.F. Kubena, J.A. Byrd, R.W. Moore, D.J. Nisbet and S.C. Ricke, 2005. Reduction of Salmonella enterica serovar enteritidis colonization and invasion by an alfalfa diet during molt in Leghorn hens. Poult. Sci., 84: 185-193.

15. McReynolds, J., L. Kubena, J. Byrd, R. Anderson, S. Ricke and D. Nisbet, 2005. Evaluation of Salmonella enteritidis in molting hens after administration of an experimental chlorate product (for nine days) in the drinking water and feeding an alfalfa molt diet. Poult. Sci., 84: 1186-1190.

16. McReynolds, J.L., R.W. Moore, L.F. Kubena, J.A. Byrd, C.L. Woodward, D.J. Nisbet and S.C. Ricke, 2006. Effect of various combinations of alfalfa and standard layer diet on susceptibility of laying hens to Salmonella enteritidis during forced molt. Poult. Sci., 85: 1123-1128.

17. Tranter, H.S. and R.G. Board, 1982. The antimicrobial defense of avian eggs: Biological perspective and chemical basis. J. Appl. Biochem., 4: 295-338.
18. Baron, F., M. Gautier and G. Brule, 1997. Factors involved in the inhibition of growth of Salmonella enteritidis in liquid egg white. J. Food Prot., 60: 1318-1323.

19. Lock, J.L. and R.G. Board, 1992. Persistence of contamination of hens' egg albumen in vitro with Salmonella serotypes. Epidemiology Inf., 108: 389-396.

20. Rizk, S.S., J.c. Ayres and A.A. Craft, 1966. Effect of holding condition on the development of salmonellae in artificially inculcated hens' eggs. Poult. Sci., 45: 825-829.

21. Stadelman, W.J. and O.J. Cotterill (eds.),1995. Egg Science and Technology, Fourth Edition. Food Products Press, $590 \mathrm{pp}$.

22. Kirunda, D.F.K. and S.R. McKee, 2000. Relating quality characteristics of aged eggs and fresh eggs to vitelline membrane strength as determined by a texture analyzer. Poult. Sci., 79: 1189-1193.

23. Humphrey T.J., 1999. Contamination of eggs and poultry meat with Salmonella enterica serovar enteritidis. In: Salmonella enterica serovar enteritidis in humans and animals: Epidemiology, pathogenesis and control (eds A.M. Saeed, R.K. Gast, M.E. Potter and P.G. Wall) pp. 183-192. Iowa State University Press, Ames, Iowa.

24. Howard Z.R., R.W. Moore, I.B. Zabala Díaz, W.K. Kim, S.G. Birkhold, J.A. Byrd, L.F. Kubena, D.J. Nisbet and S.C. Ricke, 2006. In vitro survival and growth of Salmonella Typhimurium inoculated on yolk membrane after long term refrigerated storage of shell eggs. J. Consumer Prot. Food Safety, 1: 3034.

25. Garibaldi, J.A., 1960. Factors in egg white which control growth of bacteria. Food Res., 25: 337-344.

26. Gast, R.K. and P.S. Holt, 2001b. Assessing the frequency and consequences of Salmonella enteritidis deposition on the egg yolk membrane. Poult. Sci., 80: 997-1002.

27. Gast, R.K. and P.S. Holt, 2000. Influence of the level and location of contamination on the multiplication of Salmonella Enteritidis at different storage temperatures in experimentally inoculated eggs. Poult. Sci., 79: 559-563.

28. Gast, R.K. and P.S. Holt, 2001a. Multiplication in egg yolk and survival in egg albumen of Salmonella enterica serotype Enteritidis strains of phage types 4, 8, 13a and 14b. J. Food Prot., 64: 865-868.

29. Hara-Kudo, Y., Y. Sakakibara, H. Konuma, T. Sawada and S. Kumagai, 2001. Laying season and egg shell cracks on the growth of Salmonella Enteritidis in the egg albumen during storage. J. Food Prot., 64: 1134-1137. 
30. Fleischman, G.J., C.L. Napier and S.A. Palumbo, 2003. Effect of temperature on the growth response of Salmonella Enteritidis inoculated onto the vitelline membranes of fresh eggs. J. Food Prot., 66: 1368-1373.

31. Murase, T., P.S. Holt and R.K. Gast, 2005. Growth of Salmonella enterica serovar Enteritidis in albumen and yolk contents of egg inoculated with this organism onto the vitelline membrane. J. Food Prot., 68: 718-721.

32. Gast, R.K., P.S. Holt and R. Guraya, 2006. Effect of refrigeration on in vitro penetration of Salmonella Enteritidis through the egg yolk membrane. J. Food Prot., 69: 1426-1429.

33. Gast, R.K., P.S. Holt and T. Murase, 2005. Penetration of Salmonella enteritidis and Salmonella heidelberg into egg yolks in an in vitro contamination model. Poult. Sci., 84: 621-625.

34. Clay, C.E. and R.G. Board, 1991. Growth of Salmonella enteritidis in artificially contaminated hens' shell eggs. Epidemiol. Inf., 106: 271-281.
35. Humphrey, T.J and A. Whitehead, 1993. Egg age and the growth of Salmonella enteritidis PT4 in egg contents. Epidemiol. Infect., 111: 209-219.

36. Braun, P. and K. Fehlhaber, 1995. Migration of Salmonella enteritidis from the albumen into the egg yolk. Int. J. Food Microbiol., 25:95-99.

37. Saeed, A.M. and C.W. Koons, 1993. Growth and heat resistance of Salmonella enteritidis in refrigerated and abused eggs. J. Food Prot., 56: 927-931.

38. Chen, H., R.C. Anantheswaran and S.J. Knabel, 2002. Effect of rapid cooling on the growth and penetration of Salmonella enteritidis into egg contents. J. Food Safety, 22: 255-271.

39. Theron, H., P. Venter and J.F.R. Lues, 2003. Bacterial growth on chicken eggs in various storage environments. Food Res. Inter., 36: 969975 . 